\title{
Reconhecimento de saberes locais em contexto de ambientalização*
}

\section{The recognition of local knowledge in a context of environmentalization}

Pierre Teisserenc - Professor de Sociologia Política da Universidade Paris 13, França. Fundador e atualmente vice-diretor do Centre de Recherches sur l'Action Locale (CERAL). Professor Visitante da UFPA, vinculado ao Programa de Pós-Graduação em Ciências Sociais (PPGCS) do IFCH e ao Núcleo de Meio Ambiente (NUMA). E-mail: pierre.teisserenc@wanadoo.pr

\section{Resumo}

O artigo trata da questão do reconhecimento dos saberes tradicionais no contexto de ambientalização dos movimentos sociais e de territorialização da ação pública que se acompanha habitualmente de uma reivindicação do território de pertencimento de grupos sociais. Esta reivindicação se manifesta como uma reivindicação global que abrange o estatuto das populações tradicionais, o uso da terra, as formas de producão que elas desenvolvem, seu modo de organização coletiva e o reconhecimento de sua identidade em référencia a uma cultura. Para isso é apresentada uma síntese dos debates que acompanham esta reivindicação de reconhecimento no âmbito da Amazônia brasileira e os desafios aos quais este reconhecimento deve responder, em particular sobre os laços entre o território de pertencimento e a cultura dessas populações, entre esta cultura e seus modos de ocupação e de exploração das terras e a eficácia econômica e social do modo de produção que elas têm conseguido conceber. Esta reivindicação interroga a capacidade dos saberes acadêmicos de re-interrogar a relação homem-natureza que lhes têm inspirado. Face a um tal desafio, o projeto de Edgar Morin tem pertinência e permite compreender tudo o que há de utópico em proposições como a das Reservas Extrativistas. Para concluir, voltamos às distinções entre ambientalização verde e ambientaliz̧ação marrom considerando os recursos naturais enquanto recursos patrimoniais.

\begin{abstract}
The article discusses the subject of recognition of traditional knowledge in the environmental context of social movements and territorialization of public action which usually follows a claim for territory which belongs to social groups. This claim is expressed as a global claim which comprehends the statute of traditional populations, land use, the means of production which they develop, their means of collective organization and the recognition of their identity as a culture. Therefore, the paper presents a synthesis of the debates which follow that claim of recognition within the Brazilian Amazon, and the challenges to which this acknowledgement shall respond, in special the bonds between the territory of possession and the culture of these populations; between this culture and their means of land occupation and exploration; the social and economic efficacy and the means of production that they have been able to understand. This claim questions the ability of academic knowledge to question once more the man-nature relation that have inspired them. Before such challenge, Edgar Morin's project finds all relevance and allows understanding whichever is utopic in propositions such as the Extractivist Reserves. Finally, we refer to the differences between green and brown environmentalization into consideration natural resources as heritage resources.
\end{abstract}

\section{Palavras-chave}

Reconhecimento de saberes. Populações Tradicionais. Territorialização. Ambientalização. Resex.

\section{Keywords}

Acknowledge Acknowledgements. Traditional Population. Territorialization. Environmentalization. Resex 


\section{INTRODUÇÃO}

Em artigo recente (TEISSERENC, 2010), levei em conta as interferências entre os processos de ambientalização dos movimentos sociais e os de territorialização a partir da análise de ações locais na Amazônia brasileira. Um dos resultados importantes dessa análise colocou-se no fato de que a reivindicação do território pelos diversos grupos sociais interessados se impôs como uma reivindicação global, envolvendo o estatuto social das populações tradicionais, o uso da terra, as formas de podução que elas haviam conseguido desenvolver, seus modos de organização coletiva e o reconhecimento de sua identidade em referência a uma cultura. Essa reivindicação assenta uma parte de sua legitimidade nas orientações dadas pelo movimento ambientalista internacional. Reivindicações essas assumidas pelas instâncias internacionais, como se pôde constatar na ocasião da Conferência das Nações Unidas sobre o Meio Ambiente e o Desenvolvimento (CNUMAD) realizada entre 3 e 14 de junho de 1992, no Rio de Janeiro. Há de se destacar entre as reivindicações a ideia hipotética segundo a qual as culturas das populações tradicionais seriam dotadas de predisposições em termos de saberes e perícias capazes de assegurar uma gestão sustentavel dos recursos naturais, tendo em conta as questões de conservação da biodiversidade.

O reconhecimento desses saberes está confirmado na Constituição da República Federativa do Brasil de 1988, e tem sido regularmente reafirmado em textos legislativos posteriores. Tal é o caso do $\mathrm{SNUC}^{1}$, de 2000, que definiu os objetivos da Política Nacional do Meio Ambiente e retoma as princiapais medidas em matéria de desenvolvimento sustentável e de proteção da biodiversidade. O reconhecimento legal tem conduzido muito naturalmente um certo número de experts e de lideranças a considerar que uma gestão sustentável da biodiversidade dificilmente poderia ser feita sem levar em conta a sociodiversidade.

Este artigo traz como proposta fazer um balanço do modo como as ciências sociais têm tratado esta articulação complexa entre as exigências do desenvolvimento sustentável, em matéria de gestão da biodiversidade, e do reconhecimento da sociobiodiversidade enquanto portadora de novas formas de exploração e de gestão desses recursos, graças notadamente aos saberes tradicionais que esta sociobiodiversidade possui. Portanto, ater-me-ei principalmente no exame

A tradução deste artigo, é de autoria da profa. Maria José da Silva Aquino, vinculada à Faculdade de Ciências Sociais e à linha de pesquisa "Usos Sociais dos Recursos Naturais" do Programa de Pós-Graduação em Ciências Sociais do IFCH/UFPA. E-mail: mjaq@uol.com.br

Sistema Nacional de Unidades de Conservação instituído no Brasil pela Lei 9.985, de 18 de julho de 2000. do estado dos debates atuais, limitando-me ao contexto da Amazônia brasileira, assim também a apresentar as questões que resultam desses debates em matéria de reconhecimento desses saberes e a identificar as pistas que se nos oferecem em matéria de resposta.

Esse questionamento sobre as formas de conhecimento repousa sobre o pressuposto segundo o qual os saberes têm não somente uma função e um valor acadêmico, mas que têm, ao mesmo tempo, uma função e um valor social. Esta observação prévia particularmente prova sua pertinência no momento em que os impasses postos pelo desenvolvimento ao planeta nos obriga a colocar em causa os instrumentos científicos e paradigmáticos que acompanham esse desenvolvimento e têm permitido de justificá-lo como procedente. Por conseguinte, ao lado das questões sociais, econômicas e políticas, as quais remetem à reivindicação do território pelas populações tradicionais ${ }^{2}$, existem outras questões de caráter acadêmico que concernem especificamente à maneira como os debates que dão lugar à ideia de ambientalização são ocasião de lançar um novo olhar sobre o interesse, a utilidade e a pertinência dos saberes tradicionais. Essas questões envolvem os modos de reconhecimento desses saberes e seu impacto sobre o modo de conceber o novo desenvolvimento das sociedades.

Alfredo Wagner Berno de Almeida resume nesses termos o debate que acompanha este reconhecimento:

De maneira resumida, pode-se dizer que esta forma de pensar a Amazônia abre uma nova possibilidade que transcende aquela idéia de imaginar estes sujeitos de ação ambiental como guardiões da floresta, fazendeiros ambientais... Assim, eles não podem ser mais imaginados, numa perversa divisão de trabalho, como guardando a floresta ou como preservando-a para ser usada pelos laboratórios de biotecnologia. O conhecimento científico encontra-se também nas suas experiências transformadoras, nas suas práticas, e este fato estabelece uma disputa teórica e conceitual frente a um conceito positivista de "ciência", engendrado pela dominação. Em decorrência existe uma forte articulação entre o conhecimento científico - predizido por intelectuais que intervém numa luta política seus critérios de competência e saber acadêmicos - e os movimentos sociais que não pode mais ser facilmente quebrada. Pode ser numa nova divisão do trabalho político face a questão sócio-ambiental, combinando ciência e disciplinas militantes na acumulação de um capital de conhecimentos (ALMEIDA, 2008, p. 155).

Esta "disputa teórica e conceitual", dificilmente dissociável de uma articulação entre os conhecimentos acadêmicos e os movimentos sociais, ligados estreitamente em uma divisão de trabalho político, justifica-se ainda mais, pois que

A propósito, o artigo sobre ambientalização e territorialização citado anteriormente. 
a ideia de ambientalização não se limita à elaboração e à definição de um novo conceito, que importaria integrar aos diferentes paradigmas das ciências sociais e das ciências da vida. Parece cada vez mais evidente considerar que este conceito novo nos convida a revisitar nossa maneira de pensar o real, em particular a relação entre homem e natureza, entre sujeito e objeto; estas relações a partir das quais se construíram as ciências, notadamente desde o fim do século XVII e que deram lugar a uma classificação e a uma divisão do conhecimento das quais somos herdeiros.

Eis a razão pela qual proceder a um inventário da ideia de ambientalização requer uma atualização de outros caminhos do conhecimento além daqueles que nos têm sido propostos até agora, uma vez que estamos a considerar o fato de que a constituição dos sistemas de conhecimentos traduz-se por uma partilha sábia entre saberes acadêmicos reconhecidos como legítimos e os outros tipos de saberes que Claude Lévi-Strauss identificou como componentes de um outro sistema e modo de pensamento, definido por este autor como pensamento selvagem.

Esta maneira de colocar o problema parece próxima das conclusões que se tiram pelo que expõe de sua tese:

Qualquer proposta de 'alternativa de desenvolvimento', ou de 'desenvolvimento local sustentável’ passa, portanto, por este saber acumulado, pelas formas de agregação de valor deles derivadas, e por um novo gerencialismo nas associações e cooperativas agroextrativistas, que incorpora fatores étnicos, de identidade, de gênero e de ênfase no entendimento dos sujeitos da ação... Esses conduzem às seguintes indagações: em que plano pode-se articular o conhecimento científico, crítico e responsável, com o 'conhecimento nativo' dos recursos naturais da região amazônica? Em que medida as experiências de produção em cooperativas agroextrativistas, observando os ditames das organizações ambientalistas, podem garantir a consolidação dos chamados 'saberes tradicionais'? Quais as condições de possibilidade desses saberes virem a ser incorporados e 'protegidos' por políticas governamentais num quadro em que prevalece a idéia de mercado aberto, no qual a lógica das commodities prepondera, e em que a homogeneização dos produtos da floresta tornou-se objetivo das estratégias empresariais? (ALMEIDA, 2008, p. 149-150).

Os elementos do debate são assim claramente apresentados e religados, ao mesmo tempo em que se encontram expostos alguns dos desafios resultantes em termos de qualificação de saberes (os saberes ligados à producão e à ação) de sua proteção, de sua valorização, de seu reconhecimento e de sua eventual integração aos saberes acadêmicos. $\mathrm{Na}$ verdade, o reconhecimento desses saberes e sua eventual integração aos saberes acadêmicos questionam a maneira como se constituiu historicamente a divisão social entre as disciplinas acadêmicas e a separação daí resultante entre os saberes legítimos e outras formas de saberes.

\section{COMO NÓS CHEGAMOS AQUI, NO CONTEXTO AMAZÔNICO?}

Esse debate toma lugar no fim dos anos de 1980, em um contexto de fortes polêmicas sobre as relações possíveis entre a fragilidade do ecossistema amazônico e alternativas de desenvolvimento que naquele momento eram buscadas. A crítica emana de um movimento social que se organiza em nível nacional e internacional ${ }^{3}$ e que, em resposta aos desafios da sobrevivência do planeta, preconiza uma ruptura radical com o modo de pensamento que acompanhou seu desenvolvimento e o conduziu aos impasses conhecidos hoje. No contexto amazônico, esta ruptura se apoiou sobre uma análise resultante de lutas sociais do ecossistema amazônico apresentado como o resultado de lutas sociais pelo controle do patrimônio genético através do uso de tecnologias e do reconhecimento das formas de conhecimento e de gestão dos recursos naturais próprios às populações tradicionais. Apreendido desta maneira, o ecossistema amazônico não se caracterisa somente pela riqueza de sua biodiversidade e de sua sociodiversidade, mas também como o resultado de um conjunto de relações sociais e de antagonismos que caracterizam cada território.

As alternativas ao desenvolvimento que são então buscadas visavam dois objetivos. O primeiro, de natureza jurídica, concerne particularmente à questão da criação de um direito sobre o patrimônio genético susceptível de reconhecer e de proteger as diferentes modalidades de uso dos recursos naturais e os conhecimentos específicos desses recursos pelas populações que ocupam esses territórios. O segundo objetivo, de natureza social e política, concerne à apreciação sobre a eficiência das medidas tomadas pelos poderes públicos para acompanhar o reconhecimento e a valorização dos "saberes nativos", em um contexto caracterizado pela permanência das tradições colonialistas ${ }^{4}$. Observando a esse respeito experiências de reconhecimento desses saberes a partir de iniciativas concretas de comunidades locais, Berno de Almeida constata que, com efeito, tais iniciativas “sempre consideradas 'artesanais, pré-industriais ou limitadas', não obstante sua eficácia, até então não tiveram condições históricas de ganhar corpo, dado que Amazônia foi sempre uma região 'dominada', pensada de fora e objeto permanente de projetos de inspiração colonialista” (ALMEIDA, 2008, p. 129). A

Cf. desse ponto de vista o impacto da ação de Chico Mendes e sua inteligência política para perceber o peso do interesse internacional para chamar a atenção das autoridades públicas brasileiras sobre as questões amazônicas (PORTO GONÇALVES, 2001, p. 172-173).

4 A propósito, convém lembrar a situação dos seringueiros e o sistema social do qual eles permaneceram dependentes até recentemente, mesmo após o Ciclo da Borracha (1879-1912 e 1942-45) 
realização desse segundo objetivo reterá sobremaneira nossa atenção. Não apenas por que questiona o modelo de desenvolvimento e suscita resistências importantes. Para apreciar os obstáculos a esta realização e às respostas trazidas pela resistência que ela suscita, o mais simples é reconsiderar como se organizam as atividades das comunidadaes locais e como seu modo de desenvolvimento confere a cada comunidade uma identidade em um contexto de ambientalização dos conflitos.

No artigo anteriormente citado, cuidamos notadamente de demonstar como essa ambientalização modificou os objetivos perseguidos pelos movimentos sociais. Antes da questão ambiental, o principal objetivo que eles perseguiam era a terra, assim como a propriedade e os recursos, associados à questão agrícola e, em particular, à agricultura familiar. Quando, a partir dos anos de 1980, o debate ambiental intervem, a questão se desloca para as reivindicações do território e da territorialidade - reivindicações que integram os fatores étnicos e a afirmação das identidades de diversos grupos sociais ${ }^{5}$. De fato, esses debates sobre a questão ambiental implicam diferentes movimentos sociais que se constituem então em redes nacionais e internacionais, geralmente compostas de atores heterogêneos, quer se trata de associações voluntárias e de redes da sociedade civil, de novos sindicatos preocupados em promover a agricultura familiar, cooperativas agroextrativistas, assentados em áreas de reforma agrária, grupos indígenas. $\mathrm{O}$ conjunto desses grupos sociais e atores heterogêneos vai então se encontrar em torno de reivindicações as mais diversas, em função de sua ocupação no território. Tais reivindicações são justificadas pela vinculação desses atores e grupos ao território e pela maneira como eles o ocupam, o ordenam e exploram os recursos; elas dizem respeito principalmente ao direito de uso desse território e sobre o reconhecimento das identidades e das territorialidades que as caracterizam. Esse direito de uso se justifica não somente por sua ocupação e sua vinculação ao território, mas também pela qualidade de seus saberes tradicionais, cujo reconhecimento eles esperam (ALMEIDA, 2008, p. 144). É nesse contexto de institucionalizazação de ações locais, ao mesmo tempo de sua internacionalização fundada nas reivindicações de territorialidade e de identidade que toma forma o debate sobre o reconhecimento dos saberes dessas comunidades como saberes tradicionais.

Para o nosso propósito, um elemento essencial a notar é o seguinte: esses debates levam em conta a diversidade de situações sociais e territoriais em questão,

Cf. nesse sentido a primeira parte de nosso artigo (TEISSERENC, 2010). a diversidade étnica e cultural dos grupos sociais assim como os fatores inerentes a contextos político-administrativos. São debates que dão lugar a iniciativas que têm por efeito consolidar a consciência ecológica que se nutre da identidade coletiva dos movimentos sociais. Berno de Almeida, a esse propósito fala de "um sujeito coletivo em construção, a partir de uma existência coletiva”, constituída da diversidade dos movimentos sociais e da diversidade de seus saberes em matéria de gestão da biodiversidade. Esse sujeito coletivo se beneficia da politização das denominações que permitem identificar a vida cotidiana de cada um dos grupos sociais que o compõe

"como índios, seringueiros, quebradeiras de coco babaçu, ribeirinhos, castanheiros, cstadores, pescadores etc. Registrou-se uma ruptura profunda com a atitude colonialista homogeneizante, que historicamente apagou as diferenças étnicas e a diversidade cultural. O sentido coletivo destas autodefinições emergentes impôs uma noção de identidade a qual correspondem territorialidades específicas" (ALMEIDA, 2008, p. 145).

Assim, procura-se explicar porque, na abordagem aqui proposta, a questão da identificação e do reconhecimento dos saberes tradicionais é indissociável da ambientalização dos movimentos sociais na medida em que esta ambientalização questiona a natureza das relações sociais e políticas que caracterizam a situação do ecossistema amazônico. Eis a razão pela qual nos parece indispensável, antes de apresentar um novo paradigma que envolve a questão ambiental, identificar alguns dos desafios postos ao reconhecimentos desses saberes tradicionais.

\section{DESAFIOS DO RECONHECIMENTO DOS SABERES TRADICIONAIS NA AMBIENTALIZAÇÃO DAS LUTAS?}

Para melhor apreender esses desafios é essencial voltar um instante sobre a natureza e as características desses saberes. Referindo-nos às análises de Berno de Almeida, já precisamos que uma das características desses saberes é sua apresentação como saberes práticos, no sentido em que se manifestam como o resultado de relações dialéticas entres saberes e saber-fazer, na maior parte das vezes não formalizados e integrados na cultura do grupo ou da comunidade, e as ações e práticas que inspiram os engajamentos de cada um dos indivíduos que compõem o grupo. A esta primeira características ajunta-se uma segunda que vai ao encontro de numerosas ideias recebidas e que constituiu-se objeto de inúmeras polêmicas, não 
somente entre os pensadores da modernidade mas também e sobretudo entre os antropólogos e historiadores, aquela segundo a qual a cultura de referência desses grupos ou dessas comunidades comportava uma pretensão e uma predisposição à universalidade como exprime Marshall Sahlins (2007) citando Jean-Paul Sartre: “o grupo confere seu poder e sua eficácia a indivíduos cuja particularidade irredutível é um modo de vivenciar a universalidade; ou melhor, essa universalidade assume o rosto, o corpo e a voz dos líderes que deu a si mesma (SARTRE, 1968, p. 130) ${ }^{6}$. E Marshall Sahlins observa que "Essa atribuição de poder às pessoas, em si mesma, é uma determinação estrutural” (SAHLINS, 2007, p. 297). Essa segunda característica é essencial para nosso propósito. Marshall Sahlins a justifica levando em conta a maneira como muitas comunidades tem conseguido, contrariando ideias recebidas, resistir às culturas dominantes, até mesmo se apropriar às suas maneiras disso que o capitalismo enquanto sistema de dominação comporta como características culturais e que, através da ideia de cultura como projeto, logo, "esse projeto é a indigenização da modernidade"

A uma concepção da cultura das populações tradicionais que não seria mais que o resultado de uma tradição fora da história, Sahlins opõe uma concepção da cultura apoiando-se sobre uma "tradição viva, que serve de meio e medida da inovaçao" (SAHLINS, 2007, p. 546). Ele refere-se para isso à constatação de "uma apropriação ativa" que a resistência desses grupos aos desafios do capitalismo suscitou em termos de "uma manifestação local de uma nova organização planetária da cultura". Ao invés de assistir a certo deslocamento das culturas indígenas em razão da empresa galopante do capitalismo, "o mundo também está voltando a se diversificar pelas adaptações indígenas a irresistíveis forças globais". Conclui então Sahlins: "A homogeneidade global e diferenciação local se desenvolveram juntas, esta última como uma reposta à primeria, em nome da autonomia cultural nativa" (SAHLINS, 2007, p. 545).

Incontestavelmente, é nessa perspectiva que se situa Edna Castro quando, considerando os saberes das populações tradicionais na relação com seus territórios, afirma: "Os conhecimentos das comunidades tradicionais, ainda que produzidos

\footnotetext{
6 É o próprio Sahlins que se refere a Jean-Paul Sartre para apoiar sua tese.

Marshall Sahlins (2007, p. 533-560). Capitulo 15: “Que é Iluminismo antropológico?”. Seria interessnte analisar as relações entre a ambientalização dos conflitos e do movimento social e a indigenização da modernidade. A aproximação entre os dois processos se impõe ao se leva rem conta o fato de que ambientalização dos conflitos resulta especialmente em uma diversificação dos objetos de conflitos que emanam de atores heterogêneos que se engajam em defesa de suas identidades. Não temos agora nem lugar nem os meios de ampliar uma tal análise mesmo se seu interese nos parece absolutamente fundamentado.
}

localmente, são objeto da discussão global, como, afinal de contas, também seu próprio destino" (CASTRO, 2000, p. 177). O debate global ao qual faz referência Edna Castro tem se revestido de maior atualidade e de maior fertilidade em um contexto de ambientalização.

Ao descrever em artigo anteriormente citado, a ambientalização das lutas sociais pela terra e pela apropriação do processo de produção nos mostram como o desenvolvimento desse processo se acompanhou de reivindicações de caráter cultural, simbólico e identitário que se exprimiam muito particularmente na ideia de território. Voluntariamente, temos deixado de lado as consequências que tais reivindicações poderiam ter em matéria de saberes produtivos tanto quanto de serem princípios de novas técnicas agroextrativistas, biotecnológicas e ecológicas.

A consideração de tais saberes produtivos específicos às populações tradicionais, permitiriam, segundo Enrique Leff, "construir um novo paradigma de produtividade que articula os processos ecológicos, tecnológicos e culturais, internalizando seus saberes nas práticas produtivas das comunidades" (LEFF, 2004, p. 492). Para Leff é claro que essa busca de um novo paradigma, em resposta a uma reivindicação dos movimentos sociais pela reconstrução do processo de produção está diretamente ligada a sua luta pelo território, pelas tradições e pelas suas identidades. Essa busca procede por meio de um amálgama entre os conhecimentos científicos e os saberes próprios da cultura de populações tradicionais e de suas práticas produtivas. Ela se apoia sobre uma reapropriação dos saberes pelas populações tradicionais a partir de um novo estado de relações entre natureza e cultura, da inserção dessas relações no processo de produção e de uma nova visão de mundo respeitosa às capacidades de autogestão da vida social e produtiva de cada comunidade.

Situando-se numa perspectiva próxima, Edna Castro evocou antes, a propósito, o trabalho experimental dos movimentos sociais que reivindicam a recuperação de uma identidade "outra" de seu grupo por engajamentos politicos de afirmação territorial, a partir de uma reapropriação de suas tradições étnicas e de uma recriação de seus saberes tradicionais. Assim procedendo esses grupos reinventam as maneiras de fazer a política, ao mesmo tempo em que eles reiventam seus saberes sobre a natureza e seu conhecimento das suas tradições. (CASTRO, 1999, p. 237). Como o exprimiu tão bem Edna Castro em um outro artigo: "O que está em questão é a vida - o mundo da vida como fala Habermas - e as populações tradicionais não somente estão no meio dos processos de mudanças mais profundos de nossa contemporaneidade, marcado pela intensificação da 
lógica de mercado..." (CASTRO, 2000, p. 171). O desafio de um tal trabalho é, para Enrique Leff, aquele de um processo de "re-significação do mundo" que se nutre da perspectiva de uma alternativa ao desenvolvimento atual do planeta.

Por si mesma, do ponto de vista econômico, uma tal perspectiva de alternativa não pode ser inscrita a curto prazo. Ela necessita colocar em operação transições que se caracterizariam, de acordo com Enrique Leff, por uma capacidade de articulação entre espaços econômicos autogeridos, a partir de uma apropriação comum dos recursos endógenos, e as forças onipresentes do mercado mundial. O objetivo a mais longo prazo é de desenvolver novas formas de articulação entre economias locais autogeridas, que melhorem o potencial ambiental de cada comunidade e de cada território, e conserve os recursos naturais e a biodiversidade de cada um dos ecossistemas, com uma economia global sustentável.

Apreendida a questão do reconhecimento dos saberes tradicionais no quadro de um processo de "re-significação do mundo" significa que este reconhecimento vai de par com aquele da capacidade das populações concernidas, organizadas em comunidades, a desenvolver economias locais autogeridas, integradas em uma economia global sustentável e que testemunhem a pertinência e a eficiência de seus conhecimentos tradicionais. É, em grande parte, graças a suas capacidades de iniciativas locais e à sua organização econômica e social que essas populações podem pretender o reconhecimento de seus saberes tradicionais. Assim procedendo, elas testemunham sua aptidão a promover um novo modo de produção que se imponha como uma alternativa ao modo de produção dominante. Seu projeto e as reivindicações que acompanham sua realização não se limitam, portanto, a questões econômicas e técnicas no sentido habitualmente entendido. Seu projeto e suas reivindicações são ao mesmo tempo de natureza social, cultural e política na medida em que a realização desse projeto depende de tudo o que a tornou possível. Compreende-se por que nessas condições, a questão do reconhecimento dos saberes tradicionais está estreitamente ligada à capacidade de construção de um novo sistema produtivo articulado a um território e se apresentando como o resultado das relações sociais entre as populações, de suas qualidades e de seus modos de organização, isto é, de sua territorialidade e de sua identidade.

Essa articulação do novo modo de produção inventado pelas comunidades e seu sistema social é particularmente evidenciado por Edna Castro:

"Encontramos uma integraçãoo entre a vida econômica e social do grupo, onde a produção faz parte da cadeia de sociabilidade e a ela é indissociavelmente ligada, facilitando encontros interfamiliares, realização de festas, perpetuaçao de rituais e outras modalidades de trocas nao econômicas" (CASTRO, 2000, p. 167).
A articulação forte entre o social e o econômico explica porque uma das consequências da ambientalização dos conflitos locais e dos movimentos sociais é que a reivindicação primeira é menos a do direito à terra de maneira específica, do que a do território como espaço de focalização e de convergência de reivindicações múltiplas, também diversas e articuladas entre elas, do que a dos saberes tradicionais, dos direitos ao uso da terra, das identidades etc. Disso resulta uma consequência importante sobre os fundamentos epistemológicos desses saberes tradicionais que questionam as relações do homem com a natureza. Portanto, como vamos discutir a seguir, o saber acadêmico se construiu a partir de uma oposição entre o homem e a natureza. Por ora, o que se conhece desses saberes tradicionais é que eles repousam sobre "uma concepção de terra, de direitos ao território e de identidades, como elementos que compoem um campo no qual natureza e sociedade são representados num universo unitário" (CASTRO, 2000, p. 180). Sendo assim, o reconhecimento desses saberes inevitavelmente se acompanha de uma crítica ao modo de pensamento dicotômico, o que tem prevalecido na produção dos saberes acadêmicos.

É chegado o momento, após identificadas as condições de emergência do debate sobre os saberes tradicionais das populações locais e após terem apreciado os desafios culturais, políticos e econômicos aos quais esses debate remete, de considerar a maneira como seria possível responder ao reconhecimento dos saberes tradicionais a partir do conjunto de observações que fizemos. Em particular, as observações sobre a ligação estreita entre este reconhecimento e a capacidade das populações tradicionais de conceber um sistema de produção alternativo sobre seu território de pertencimento capaz de se integrar a uma economia global sustentável.

\section{UM NOVO MODO DE PENSAMENTO DAS RELAÇÕES HOMEM-NATUREZA}

Segundo Enrique Leff, para apreender um novo modo de pensar relações homem-natureza, é essencial certo distanciamento em relação à ecologia e partir das características do "meio ambiente". O que caracteriza esse meio é a complexidade ambiental, que seria segundo ele a imagem da complexidade do mundo. Esta complexidade questiona as formas de apropriação do mundo e da natureza pelo homem; formas de apropriação que tem sido a origem das formas dominantes de conhecimentos e que são ao mesmo tempo relações de poder. 
A crítica da ecologia que desenvolve nesta ocasião Enrique Leff o conduz a propor uma maneira de apreender o meio ambiente, que não corresponde em nada à ideia de um meio composto somente de espécies e populações biológicas. O meio ambiente não seria segundo este autor nem uma categoria geográfica nem uma categoria biológica. Mas uma categoria sociológica que foca comportamentos, valores e saberes das populações que ocupam o meio em questão, ao mesmo tempo em que foca potencialidades produtivas que escondem este cojunto de saberes, valores e comportamentos. Para qualificar sua abordagem do meio ambiente, Enrique Leff fala por seu turno de "racionalidade social" e de "racionalidade ambiental”. Pessoalmente, je não estou certo que esse conceito de racionalidade traz algo esclarecedor ao debate. Mas, o essencial é, sobretudo, na ideia segundo a qual, se uma racionalidade nova existe, é para distingui-la daquela que prevalece no campo econômico, científico e tecnológico; a racionalidade da modernidade, cuja potência se manifesta notamente pela marginalização e submissão dos saberes tradicionais à centralidade do logos científico.

Em tal perspectiva, o reconhecimento dos saberes tradicionais passa por uma transformação dos paradigmas científicos atuais e pela producão de novos conhecimentos e de novas maneiras de produzir conhecimento, a partir de um diálogo, de um confronte, de uma hibridação e de uma integração desses saberes, com o apoio das diferentes disciplinas para promover uma organização interdisciplinar dos conhecimentos a serviço de um desenvolvimento sustentável (LEFF, 2006, p. 161).

Essa mudança de perspectiva necessita reintroduzir a complexidade lá onde as ciências modernas procedeu à simplificação. A complexidade do real multiplicando as articulações entre a física, a biologia e os fatores culturais, mas igualmente entre a economia, as tecnologias e a vida cotidiana e os marcos simbólicos das populações tradicionais para facilitar a emergência de uma “ordem produtiva sustentável” e isso, a partir de uma organização social, de uma produtividade ecológica e de uma potência tecnológica. Trata-se igualmente de reintroduzir a complexidade nos próprios conhecimentos, ressoando neles a crise causada pela dominação da natureza e seus efeitos, permitindo assim a emergência de novas formas de saberes marcados pela consideração da diferença e por formas de hibridação entre as ciências modernas, as tecnologias e os saberes tradicionais.

Trata-se também da complexidade da produção procedendo a uma internalização das externalidade não econômicas; em particular, aquelas sob exigências de conservação da biodiversidade e de um meio ambiente sustentável. Tais exigências merecem ser consideradas como um potencial produtivo fundado sobre uma produtividade tecnológica e cultural que se nutra da capacidade de invenção e de criação das comunidades desde que seus saberes tradicionais adquiram legitimidade e reconhecimento.

E trata-se, enfim, de uma complexidade do tempo que consiste a recolocar os elementos de uma história antiga, marcada pelas conquistas e submissões resultantes, e de tratá-las para abrir esta história a uma atualidade que se esforça para dar sentido às tradições, de inaugurar novas trilhas e de facilitar a emergência de novas identidades, a partir de uma ressignificação do mundo em termos de alteridade, de diversidade, de diferença, de pluralidade e de uma reapropriação do território ${ }^{8}$.

Esta articulação entre o trabalho de reconhecimento dos saberes tradicionais e a reivindicação do território é igualmente evidenciada por Edna Castro, ao apresentar a natureza desses saberes como

"uma adaptação a um meio ecológico de alta complexidade" resultante de "saberes acumulados sobre o território e das diferentes formas pelas quais o trabalho é realizado. Suas atividades apresentam-se complexas, pois constituem formas múltiplas de relacionamento com os recursos, e é justamente essa variedade de práticas que assegura a reprodução do grupo" (CASTRO, 1997, p. 226).

Este uso dos recursos e a diversidade das práticas que este uso gera são totalmente integradas ao modo de vida das populações tradicionais, em particular os quilombolas, e são transmitidos através de gerações, ao mesmo tempo que eles são elementos constitutivos de uma concepção do território que Edna Castro define como um patrimônio comum. Apreender, em termos de patrimônio, a questão dos saberes tradicioanis próprios a um grupo social e a sua capacidade de se organizar sobre um território, é entrar no debate sobre a biodiverisade social e a necessidade de respeitar e de preservar "os direitos das populações tradicionais, direitos referidos ao território e aos seus modos de vida... a questão que se coloca é de proteger as culturas, os saberes herdados do passado enquanto patrimônio acumulado por gerações" (CASTRO, 1997, p. 230).

O debate aqui abrange questões jurídicas que Edna Castro evoca e às quais já fizemos referência; não vamos retomá-las mesmo se são essenciais ao debate. Privilegiaremos as questões econômicas e sociais que o debate permite identificar,

8 Cf. a propósito o que afirma Edna Castro sobre a importância do reconhecimento do território para os quilombolas do qual depende o estabelecimento de sua identidade e a revalorização de seus saberes tradicionais e tradições étnicas (CASTRO, 1997, p. 235). 
em particular por seus efeitos nas mudanças de objetivos da luta dessas populações que, simultaneamente, reivindicam uma terra sobre a qual testemunham suas capacidades de promover um novo modo de produção, e buscam fazer valer os conhecimentos e os savoir-faire, sua capacidade de inovação que está na origem desta nova maneira de produzir: "O campo da luta não é mais apropriação do território em si, mas o acesso e o controle do conhecimento ... Impossível de proteger a diversidade biológica sem proteger, concomitantemente, a sociodiversidade que a produz e conserva" (CASTRO, 1997, p. 234). Nesta perspectiva, a luta pelo território é indissociável da luta pelo reconhecimento da capacidade de proteção da biodiversidade pelas populações tradicionais; capacidade que testemunha sua competência na matéria. Eis a razão pela qual o reconhecimento desses saberes tradicionais se apresenta como o ponto nodal da interferência e do resultado do duplo processo de ambientalização e de territorialização.

Do ponto de vista da formalização desta abordagem inovadora, Edgar Morin é provavelmente o autor que melhor conseguiu tomar em consideração esta nova problemática e propor uma interpretação susceptível de responder aos desafios do reconhecimentos dos saberes tradicionais. A propósito, é significativo que numerosos autores brasileiros refiram o seu pensamento deste autor quando estão a tratar deste assunto. Segundo Edgar Morin, os paradigmas científicos atuais têm respondido ao desejo do homem em dominar a natureza; e neste domínio corre o risco de destruí-la. É significativo também que nestes paradigmas tenham-se elaborado, a partir de uma relação particular sujeito-objeto, uma relação de exterioridade do objeto em relação ao sujeito e de vontade de objetivar o objeto em sua relação com o sujeito. É essencial lembrar isso no momento onde, a evolução recente dessas ciências sob o efeito dos desafios aos quais elas são levadas a responder, os limites a um esforço de reelaboração para habilitá-los a melhor intergrar a complexidade da vida. Desse ponto de vista, é significativo ainda que desde alguns anos a ideia de ciências humanas e de ciências sociais tenham apresentado tendência a dar lugar à ideia de ciências da vida.

O novo paradigma que, segundo Edgar Morin, permitiria melhor responder a tais desafios repousa antes de tudo sobre a ideia de uma inclusão recíproca e recursiva das relações do homem com a natureza, do sujeito com o objeto. Trata-se de ter em conta uma relação complelxa e paradoxal que consiste em considerar a vontade de autonomia da vida reconhecendo sua dependência de recursos externos que contribuem com sua autonomia, desde que se consiga conservá-los. A isso Edgar Morin chama "auto-eco-organização" "É isto que Edgar Morin chama de inclusão 9. CPor um pensamento ecologizado" (MORIN, 1997, p. 53-78). recíproca e requer a apropriação da ideia que o exterior é ao mesmo tempo o interior, que o sujeito é ao mesmo tempo o objeto, que a ideia é ao mesmo tempo a realidade. Assim o macroeconômico ao qual remete o exterior é ao mesmo tempo o microssocial ao qual remete o interior. Esta ideia nova então se impõe: entre o interno e o externo não existe somente uma relação; existe uma inclusão mútua. O homem não está somente em relação com o ecossitema; ele faz parte do ecossistema, da biosfera, do cosmos. Nós somos certamente autônomos, mas em relação ao cosmos e ao mundo. É isso que Edgar Morin chama de paradigma "hologramático".

Dessa maneira Morin considera como parte de nossa realidade a necessidade de empreender um trabalho de civilização desse mundo porque

“nossas idéias são bárbaras, e nós somos seus escravos, sem nem mesmo compreender que fomos nós mesmos que as geramos... As idéias são produtos qe se tornam nossos próprios produtores, pois, para nos tornarmos mais humanos, precisamos das idéias" (MORIN, 1997, p. 76).

Daí decorre não somente um modo de pensamento ecológico, mas um modo de pensamento ecologizado que permite explicar como todos os fenômenos sociais são autônomos e interdependentes ao mesmo tempo. Edgar Morin dá o exemplo dos deslocamentos em todas as cidades do mundo que conhecem os efeitos de saturação, apesar da existência de regras, de regulamentos e de programas de gestão; ao mesmo tempo, esta saturação da circulação é acompanhada de sua autoregulação, segundo modalidades próprias a cada um contexto urbano. Todas as cidades do mundo, como Nova York, São Paulo, Paris, Londres, Teerã etc. comportam congestionamentos monstros; mas em cada uma dessas cidades, apesar da semelhança das regras e regulamentos, não se lida com o problema da mesma maneira.

Isso significa que todo grupo social desenvolve uma capacidade de autoorganização que repousa em parte sobre relações autônomas e espontâneas entre os indivíduos e os grupos que compõem a sociedade. Esta capacidade de autoorganização testemunha ao mesmo tempo uma capacidade de eco-organização, que leva cada grupo social a ter em conta a internalização dos constrangimentos externos, precisamente os que correspondem às exigências da ambientalização. $\mathrm{O}$ laço entre essas duas capacidades funda e justifica necessariamente a existência de uma maneira ecológica de apreender a realidade social. Segundo Edgar Morin, esta maneira de pensar constitui uma via de acesso muito importante ao pensamento complexo. A isso ele logo acrescenta que é essencial que "o pensamento complexo integre também necessariamente em si a dimensão ecológica” (MORIN, 1997, p. 67). 
Como chegar a um tal resultado? Do lado do sistema de produção, pelo meta-desenvolvimento que consiste em civilizar a civilização das máquinas e da engenharia introduzindo fatores da complexidade da vida no processo de produção, porque sem isso estaria-se na incapacidade de conciliar o objetivo da conservação da biodiversidade e o objetivo do desenvolvimento tecnológico por meios novos e complexos. Procedendo assim, opera-se uma revolução copernicana. Qual seja: passa-se de uma lógica de destruição, que caracteriza habitualmente o modo de desenvolvimento tecnológico moderno, a uma lógica de regulação entre o desafio da conservação e o da inovação; porque, com efeito, para inovar nesta nova maneira de apreender a realidade essencial se torna conservar e valorizar as diversidades naturais, biológicas e culturais.

Colocando-se a conservação e a valorização das diversidades naturais e culturais no centro da regulação, esse novo paradigma das relações entre homem e natureza confere uma posição destacada aos saberes tradicionais e a sua articulação com o desenvolvimento tecnológico, próximo do sentido proposto por Enrique Leff em termos de integração e hibridização. Trata-se de um paradigma multidimensional que se desenvolve na interface entre um processo de auto-ecoorganização dos grupos sociais implicados e a traducão desta auto-organização em uma capacidade de autoprodução. O reconhecimento desses saberes é indissociável de uma capacidade de organização inovadora, tanto quanto de um modo de regulação que permita a essas duas a capacidade de funcionar em harmonia.

Desse modo, tal paradigma se apresenta como um paradigma radical no sentido de oferecer possibilidades novas de pensar a maneira de viver e de habitar do homem, em uma nova relação do homem com a natureza, relação unificada como a entende Edna Castro. Por isso, esse paradigma questiona a política enquanto responde às exigências de um modo de pensar planetário e complexo, explicando as diversidades culturais localizadas em um contexto de globalização como Marshall Sahlins esforça-se em considerar.

\section{CONSEQUENCIAS POLÍTICAS E SOCIAIS DESSE NOVO PARADIGMA: A RESEX COMO UTOPIA}

Proponho-me apresentar as consequências políticas e sociais desse novo modo de apreensão das relações homem-natureza, inspirando-me, a título de exemplo, na situação das Resex e nos trabalhos aos quais sua operação tem dado lugar. Em artigo recente (TEISSERENC, 2010), analisei Resex enquanto instrumento de uma política pública, ambiciosa e inovadora do Estado brasileiro. Nesse artigo insisti particularmente na importância em se ter em conta a história deste instrumento para compreender a complexidade e as dificuldades encontradas em sua aplicação. Agora, retomo esta mesma ideia da história do instrumento para explicar sua possibilidade em contribuir com respostas aos desafios do reconhecimento dos saberes tradicionais.

Em sua análise do fenômeno da re-existência seringueira, Carlos Walter Porto Gonçalves apresenta o projeto Resex inicado por Chico Mendes, no início dos anos de 1980, como uma proposição política original a combinar luta pela terra com luta por um modo de vida. O projeto Resex é então descrito como "um laboratório vivo para a busca de um modelo de desenvolvimento que se faça com e a partir de populações que tem um saber efetivo tecido na convivência na floresta" (GONÇALVES, 2001, p. 132). Esta referência à ideia de uma Reserva à imagem de um laboratório se justifica, principalmente, porque a proposição de Resex, iniciada por Chico Mendes e seus companheiros de luta, é acompanhada de uma reconciliação significativa entre o mundo acadêmico, o movimento social e o sindicado presidido por ele, reconciliação que criou condições de inovação e de uma legitimação de seus resultados.

Além disso, a ideia da Resex como laboratório resulta do fato que sua operação repousa sobre relações novas e originais entre o Estado e a sociedade civil, que se esforçam em combinar melhor a propriedade de um bem comum cedido à comunidade com a possibilidade de um usufruto a beneficiar cada família individualmente sob a tutela do Estado e em uma concepção participativa da gestão desse bem, com o objetivo de garantir o uso sustentável dos recursos. Como tal, o projeto Resex se apresenta bem relevante como um trabalho, no sentido que confere Edgar Morin, de auto-organização e autoprodução, simultaneamente. O diálogo permanente com o Estado federal, que institui o projeto e confere à Reserva uma legitimidade que se achou reforçada pela atribuição de recursos específicos. Este diálogo deveria igualmente ser levado a desempenhar um papel em matéria de regulação local; um papel certamente parcial na medida em que esta vontade demonstrada de diálogo não resolveu a espinhosa questão das relações entre Conselho Deliberativo de que se dota a Reserva para assegurar sua gestão e organizar seu território e o poder local. 
A reconciliação preconizada pelo projeto Resex entre os cientistas, os técnicos e as populações tradicionais, organizadas em comunidades e engajadas no movimento social, cria as condições de um debate sobre a pertinência dos saberes locais, ao mesmo tempo que abre perspectivas interessantes ao reconhecimento desses saberes e habilidades quando eles se concretizam em ações locais que contribuem ao melhoramento da qualidade de vida dessas populações, respeitandose as exigências do desenvolvimento sustentável. Esses resultados esperados em termos de elevação da qualidade de vida se manifestam, em particular, por uma diversificação da producão, pela emergência de novos modos de comercialização desses produtos e por sua integração no mercado. A Resex aparece, assim, não somente como um instrumento de política pública assumindo uma história particularmente forte e original, mas também como um laboratório vivo onde se experimenta, sobre um território, um novo modo de desenvolvimento em sintonia com os desafios da ambientalização, ao levar em conta saberes das populações tradicionais. A pertinência desses saberes, acoplada à diversificação da producão, e à integração daquela ao mercado.

Como tal a Reserva se apresenta como uma proposta utópica, apoiada por uma experiência social (GONÇALVES, 2001) que deve, para ser bem sucedida, modificar a estrutura fundiária pelo desenvolvimento de relações contratuais entre o Estado, as comunidades e seus membros, e por uma mudança das relações econômicas e sociais baseadas em uma nova concepção da gestão dos recursos do território e um novo modo de partilha desses mesmos recursos.

\section{CONSIDERAÇÕES FINAIS}

\section{O reconhecimento dos saberes tradicionais entre a ambientalização verde} e a ambientalização marrom

O que acabamos de evocar, como exemplo, a propósito das Resex poderia se aplicar a alguma nuance do conjunto dos territórios amazônicos que estão crescentemente atingidos pela criação de áreas protegidas de toda natureza assentamentos, Reservas Indígenas ou territórios quilombolas. Todas essas criações, que participam à sua maneira da ambientalização dos territórios amazônicos, oportunizam ao seu modo debates locais que podem estar relacionados aos saberes tradicionais, sua pertinência e sua legitimidade em termos de experiências que testemunham a capacidade produtiva das populações tradicionais.
Em artigo absolutamente apaixonante sobre "ambientalização dos conflitos sociais" José Sérgio Leite Lopes distingue dois contextos: verde e marrom. Não retomarei aqui certa reserva à formulação dessas diferenças ${ }^{10}$. Gostaria, no entanto, de tentar responder à questão de saber em qual medida a existência e a consideração dos saberes tradicionais constituiriam a diferença mais significativa entre a ambientalização verde e a ambientalização marrom. De fato, nos contextos de ambientalização marrom, os saberes tradicionais não estão em questão, mesmo quando se fala em populações tradicionais. Isso basta para responder pela negativa de maneira definitiva e esta questão? Certamente não. É também o próprio Leite Lopes que abre um debate interessante quando, na conclusão de seu artigo, menciona a situação dos territórios desindustrializados da Europa ${ }^{11}$ que vivem situações de re-desenvolvimento a partir de uma valoraização de seus recursos enquanto "patrimônio material, imaterial, historico e cultural" (LOPES, 2006, p. 59).

Muitos trabalhos sociológicos e antropológicos na Europa dão conta da importância desse patrimônio imaterial que representa certas habilidades locais resultantes geralmente de uma antiga tradição monoprodutiva sobre um território e que se manifestam pela existência de culturas locais e identidades territoriais fortes $^{12}$. Mas, de fato, ao meu conhecimento e à diferença do que se passa no quadro de ambientalização verde, a existência de um tal patrimônio imaterial não dá geralmente lugar a reivindicações coletivas visando seu reconhecimento e não produz, portanto, efeitos em termos de mobilização local. Para explicar as razões das dinâmicas locais que se traduzem em efeitos de desenvolvimento territorial, a

10 Apresentei essas reservas na conclusão do artigo (TEISSERENC, 2010). In : Antropolitica $\mathrm{N}^{\mathrm{o}} 29$, segundo semestre de 2010. Revista Contemporânea de Antropologia, Programa de Pósgraduação em Antropologia, Universidade Federal Fluminense, ISSN 1414 -7378. No prelo.

11 ECKERT, C. (1993), "Memória e identidade: ritmos e ressonâncias da duração de uma communidade de trabalho, mineiros do carvalhao (La Grand-Combe, França)", Cadernos de Antropologia, Porto Alegre: PPGAS, $\mathrm{n}^{\circ} 11$.

12 DENIEUIL, P. N. (1997), Lien social et développement économique. Paris: l'Harmattan. Collection Logiques sociales; GAGNON, C. (1994). La recomposition des territoires. Développement local viable, L'Harmattan, Collection Logiques sociales, Paris; GANNE, B. "Les approches du local et les systèmes industriels locaux". In: Sociologie du travail, XXXIII, 4/1991, 545-576; MERCIER, N. et SEGRESTIN, D." "L'effet territoire dans la mobilisation ouvrière - Essai d'analyse de situations complexes". In: Revue française de sociologie, janvier-mars 1983, p.61-79; MERCIER, N. et SEGRESTIN, D. "Des ouvriers sur leurs terres - Deux études de cas comparés”. In: Sociologie du travail, 2/1983, p. 147-169; SAGLIO, J. "Deux études de cas comparés". In: Sociologie du travail, 2/1983, p. 147-169; SAGLIO, J. XXXIII, 4/1991, p. 529-544; TEISSERENC, P. (2002). Les politiques de développement local. Économica, 2de Édition, Collection "Collectivités Territoriales", Paris; TEISSERENC Pierre, Le développement par la culture. In: L’Homme et la société, 1997/3, n¹25, p.107-121. 
grande parte dos trabalhos existentes tem acentuado, antes de tudo, os aspectos institucionais, a natureza dos sistemas do ator, as alianças em termos de poder local, ou ainda as qualidades estratégicas e culturais dos atores e das redes em sua capacidade de se renovar e inovar.

A abordagem mais recente das questões de biodiversidade, em termos de patrimônio, abre perspectivas novas. O fato de os questionamentos que daí resultam não limitarem os empreendimentos pelo re-desenvolvimento a referências puramente econômicas, dando lugar às dimensões sociais e ambientais, cria uma situação nova que abre perspectivas interessantes às ciências sociais, desde que se disponham a renovar seus referenciais e seus métodos de trabalho, esforçando-se notadamente em aplicar o quadro de análise sugerido por Edgar Morin e sua escola de pensamento. É claro que se o impulso mais forte e o mais interessante, em matéria de ambientalização vem dos contextos verdes, como é o caso da Amazônia, o impacto econômico, social e político deste impulso emergirá reforçado se se provar que os dois contextos, marrom e verde, passem por transformações não somente analógicas, mas convergentes em matéria de resultados econômicos, sociais, culturais e políticos.

\section{REFERÊNCIAS}

ACSELRAD, H. Ambientalização das lutas sociais - o caso do movimento por justiça ambiental. Estudos Avançados, v. 24, n. 68, p. 103-119, 2009.

ALMEIDA, A. W. B. Antropologia dos Archivos da Amazônia, Casa 8. Rio de Janeiro: F.U.A, 2008.

CASTRO, E. Território, Biodiversidade e Saberes de Populações Tradicionais. In: DIEGUES, A. C. Etnoconservação: Novos Rumos para a Proteção da Natureza nos Trópicos. 2. ed. São Paulo: USP/Nupaub; Hucitec, 2000.

CASTRO, E.; PINTON, F. Faces do Trópico Úmido. Conceitos e Questioes Sobre Desinvolvimento e Meio Ambiente. Belem: Cejup, 1997.

DURAN, P.; THOENIG, J-C. L'État et la gestion publique territoriale. Revue Française de Science Politique, v. 46, n.4, p.580-623. Août. 1996.

DENIEUIL, P. N. Lien social et développement économique. Paris: l'Harmattan, 1997. (Collection Logiques sociales).
GAGNON, C. La recomposition des territoires. Développement local viable. Paris: L'Harmattan, 1994. Collection Logiques sociales).

GANNE, B. Les approches du local et les systèmes industriels locaux. In: Sociologie du travail, v. 33, n. 4, p. 545-576, 1991.

HAESBAERT, R. O mito da desterritorialização. Rio de Janeiro: Bertrand Brasil, 2004.

LEFF, E. Epistemologia Ambiental. São Paulo: Cortez Editora, 2002.

LEFF, E. Racionalidade Ambiental. A reapropriaçao social da natureza. Rio de Janeiro: Civilizaçao Brasileira, 2006.

LEITE LOPES, J. S. Sobre processo de “ambientalizaçao" dos conflitos e sobre dilemas da participaçao. Horizontes Antropológicos, Porto Alegre, v. 12, n. 25, jan./jun. p. 31-64, 2006.

MERCIER, N.; SEGRESTIN, D. L'effet territoire dans la mobilisation ouvrière - Essai d'analyse de situations complexes. Revue française de sociologie, jan.mar., p. 61-79.1983,

MERCIER, N.; SEGRESTIN, D. Des ouvriers sur leurs terres - Deux études de cas comparés. Sociologie du Travail, v. 2, p. 147-169, 1983.

MORIN, E. Por um pensamento ecologizado. In: CASTRO, E.; PINTON, F. (Org.). Faces do Trópico Úmido: Conceitos e Questões Sobre Desenvolvimento e Meio Ambiente. Belém: Cejup, 1997. p. 53-78.

PORTO GONÇALVES, C. W. Amazônia, Amazônias. São Paulo: Editora Contexto, 2001.

SAGLIO, J. Echange social et identité collective dans les systèmes industriels. Sociologie du travail, v. 33, n. 4, p. 529-544, 1991.

SAHLINS, M. Cultura na Prática. 2. ed. Rio de Janeiro: Editora da UFRJ, 2007. SANTOS, M. A Natureza do Espaço: Técnica e Tempo. Razão e Emoção. São Paulo: EDUSP, 2002.

SARTRE, J-P. Search for a Method. Tradução de Hazel E. Barnes. Nova-York: Doubleday, 1968.

TEISSERENC P. Le développement par la culture. L'Homme et la société, n.125, p.107-121, 1997. 
TEISSERENC, P. Les RESEXs, un instrument au service des politiques de développement durable en Amazonie brésilienne. Revista Pós Ciencias Sociais, n. 12, p. 41-68, fev. 2010. (Dossiê Amazônia e Paradigmas de Desenvolvimento) TEISSERENC, P. Les politiques de développement local. Économica. 2. ed. Paris, 2002. (Collection Collectivités Territoriales)

TEISSERENC, P.; ROCHA, G.; MAGALHÃES, S. Território de Desenvolvimento e Ações Públicas. Belém: Ed. UFPA, 2009. p. 23-64.

TEISSERENC, P. Ambientalização e territorialização: situando o debate no contexto da Amazônia brasileira", in Revista Antropolitica, n. 29, jul.-dez. 2010. VIEIRA DE MEDEIROS, R. M. Território, Espaço de Identidade. In: SAQUET, M. A.; SAVERIO SPOSITO, E. Territórios e Territorialidades. Teorias, processos e conflitos. São Paulo: Expressão Popular, 2009.

Texto submetido à Revista em 20.4.2010

Aceito para publicação em 13.9.2010 